This item was submitted to Loughborough's Research Repository by the author.

Items in Figshare are protected by copyright, with all rights reserved, unless otherwise indicated.

\title{
High value information in engineering organisations
}

PLEASE CITE THE PUBLISHED VERSION

PUBLISHER

(C) Elsevier

LICENCE

CC BY-NC-ND 4.0

REPOSITORY RECORD

Zhao, Yuyang, L.C.M. Tang, M.J. Darlington, Simon A. Austin, and S.J. Culley. 2019. "High Value Information in Engineering Organisations". figshare. https://hdl.handle.net/2134/3904. 
This item was submitted to Loughborough's Institutional Repository (https://dspace.lboro.ac.uk/) by the author and is made available under the following Creative Commons Licence conditions.

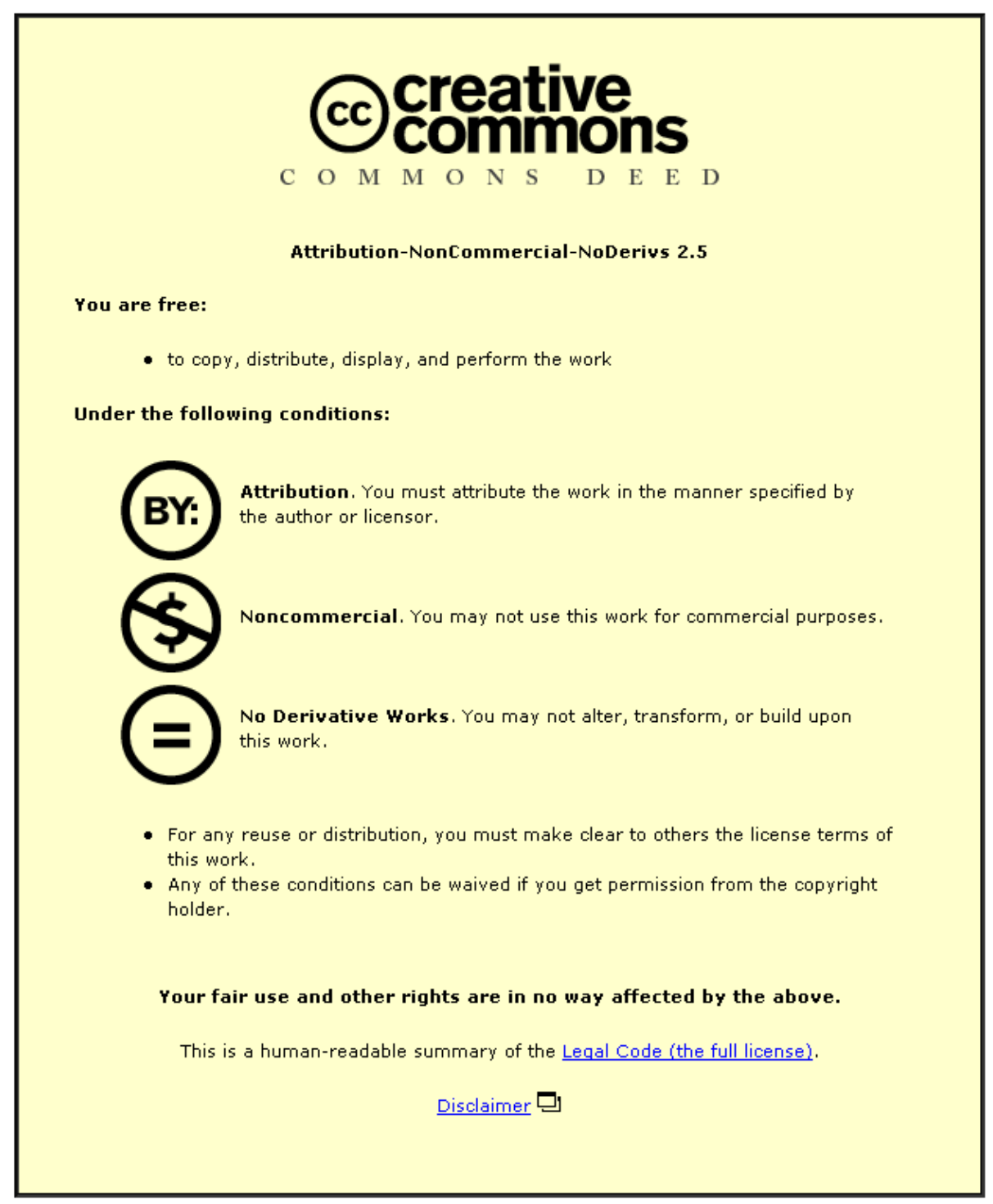

For the full text of this licence, please go to: http://creativecommons.org/licenses/by-nc-nd/2.5/ 


\title{
High Value Information in Engineering Organizations
}

\begin{abstract}
The management of information in engineering organizations is facing a particular challenge in the ever-increasing volume of information. It has been recognized that an effective methodology is required to evaluate information in order to avoid information overload and to retain the right information for reuse. By using, as a starting point, a number of the current tools and techniques which attempt to obtain 'the value' of information, it is proposed that an assessment or filter mechanism for information is needed to be developed. This paper addresses this issue firstly by briefly reviewing the information overload problem, the definition of value, and related research work on the value of information in various areas. Then a "characteristic" based framework of information evaluation is introduced using the key characteristics identified from related work as an example. A Bayesian Network diagram method is introduced to the framework to build the linkage between the characteristics and information value in order to quantitatively calculate the quality and value of information. The training and verification process for the model is then described using 60 real engineering documents as a sample. The model gives a reasonable accurate result and the differences between the model calculation and training judgments are summarized as the potential causes are discussed. Finally several further the issues including the challenge of the framework and the implementations of this evaluation assessment method are raised.
\end{abstract}

Keywords: Value, Information, Information Evaluation, Bayesian Network 


\section{Introduction}

There are a number of challenges associated with managing information in engineering organizations, and in particular the ever-increasing volumes of information, its continuously changing nature and the wide variety of uses of even the same information. It has been recognized that an effective methodology is required to be established to evaluate information in order to avoid information overload and to retain the right information for reuse. Little seems available, however, to help organisations address these challenges. The authors propose an assessment or filter mechanism for information can be developed, utilising a combination of existing tools and techniques which attempt to evaluate 'the value' of information.

Value is a key to a successful business, yet, like information and knowledge, it can be an elusive concept. Tools and methodologies exist for valuing intangible assets in engineering, project management, financial, accounting and many other fields, but they do not address fully the issues associated with valuing information. However the existing works in a variety of fields, such as supply chain management, network risk analysis, decision making support in management, financial and accounting, and in the library sector, can be referred to the efforts of putting value on information in some degree. The approaches have limitations when being used in the context of engineering design while there is some potential for supporting information activities. In addition, it is seen that the characteristics which make information a high quality asset are also one key to support the evaluation process.

As the quantity of available information increases, its quality becomes an ever more important factor for the effectiveness of organizations and individuals. Information quality has been a longstanding concern within many approaches in a variety of domains; what these approaches have in common is their primary concern with providing the right information, in the right format and quantity, at the right time, to the right person, and at reasonable cost. These requirements relate to a variety of information characteristics. There is a clear connection between quality and value of information but this is not necessarily in direct proportion as will be discussed later. If the information characteristic criteria can be regarded as individual nodes forming an evaluation network, a mathematical method could be developed to carry out the calculations through the network, to support the evaluation assessment and reasoning diagnosis process. A quantitative evaluation of information can be obtained through this calculation method. Moreover decision support based on assessment and reasoning diagnosis could also be developed.

The paper is organized as follow: in Section 2, a review of information overload, value and value of information is introduced; then in Section 3, an information evaluation approach is presented; Section 4 discusses a preliminary decision support model based on information evaluation and the 
potential benefits and resources; finally Section 5 concludes by outlining the requirements and challenges when implementing such an approach in the context of engineering design.

\section{Information value}

The information overload problem is significant and is exacerbated when through-life activities which generate large amounts of information and knowledge - are considered. This information overload problem has been a topic of discussion for approximate 20-30 years and various solutions have been proposed such as concurrency management, new push technology, intelligent agents, and so on (Edmunds \& Morris, 2000). Putting a value on information to help to judge what to retain and what to discard is an obvious potential solution and previous work will be discussed in later sections.

\subsection{Information overload}

Modern industries are becoming more dynamic in nature due to the diverse and complex nature of work tasks, trading relationships, environments, as well as the temporary and transitory nature of workplaces and workforces. Information can be viewed as an asset of a corporate body, whilst at an operational level appropriate and timely information is very important to the success of a project or a design. If, as is widely argued, information and knowledge are commodities (Hicks \& Culley, 2002) then it is truism for both the individual and the corporate body that they can only afford to acquire and maintain so much. This is not solely for financial reasons, but because of the limits of storage capacity and restricted processing capabilities. However, until recently, the approach of many organisations has been to gather all information regardless of the cost, which leads to what can be thought of as information waste and a cost burden. A recent survey (Inc. Staff, 2003) revealed that 80 percent of information filed has never been used. Furthermore, it has been widely reported that the performance of an individual or an organisation can be detrimentally affected by too much information (Butcher, 1995; Eppler \& Mengis, 2004).

The problem of information overload is increasing as new technological developments are fast growing (Feather, 1998). Information burdens, including personal, organisational and customer loading (Edmunds \& Morris, 2000), can have a variety of side effects on people and the organisation such as low productivity and stress leading to "information fatigue syndrome” (Lewis, 1996; Oppenheim, 1997). Many organisations are aware that these problems generate some fundamental questions such as: how much information does an organisation need? Which pieces of information does an organisation need? And when does the organisation need them? (Eppler \& Mengis, 2004). In particular, there can be a failure to learn from previous experience because the information has not been captured or it is not readily retrievable in a meaningful context. The latter problem may well be compounded by being lost amongst all the data. 
Finding answers to these questions is important for any organisation operating in any business sector. However, in the highly competitive global engineering markets the resolution of these issues is particularly critical. This is because of the information-intensive nature of engineering and construction processes, and in particular the design process, which relies upon and generates large amounts of information during its execution (Thomson \& Austin, 2003). Answering these questions is made more complicated by the fact that there is a combination of creative processes, with team activities, and also within and without of organisations undertaking large parts of the activity. In the construction and engineering sector contexts, information can be easily captured but relevant information that may be ready for reuse for the next project or next generation is not easy to be identified along the information life cycle (Tang et al., 2006).

\subsection{Value}

Value is a widely used, but poorly defined term. In the abstract sense value encapsulates the core beliefs, morals, and ideals of individuals and is reflected in their attitudes and behaviour in society. Kohler said that "At the bottom of all human activities are values, the conviction that some things 'ought to be’” (Kohler, 1966). Although valuation is a common process when people make a judgment or assessment with regard to their beliefs and expectations, the concepts, definitions and methodologies of valuation are very different in various fields.

From a philosophical point of view, Dent stated that value comprised “...three connected issues: first, on what sort of property or characteristic 'having value' or 'being of value' is; second, on whether having value is an objective or subjective matter, whether values repose in the object or is a matter of how we feel towards it; third on trying to say what things have value” (Dent, 1995). When assessing an object, people make judgments with regard to their beliefs and expectation such as the 'users' values, their goals, and the product the associated services, uses, and the situation being encountered (Woodruff \& Gardial, 1996). From this social point of view, value is a perception and it is not measurable. However, despite its subjective nature, objective interpretations of value are commonplace and are widely adopted in most fields and typically expressed as a price.

In the manufacturing sector, Miles suggested that the definition of value varies with the purpose, viewpoint and intent of the person who defines it. He identified four forms of value: use, esteem, cost and exchange value (Miles, 1972). Fowler (1990) too recognized that for a product, value is how it fulfils a user's need so that:

$$
\text { Value }=\frac{\text { Worth }}{\text { Cost }}
$$

However he also recognized the difficulty of measuring the worth and suggested an alternative expression with a more subjective view: 


$$
\text { Value }=\frac{\text { User initial impression }+ \text { satisfication in use }}{\text { First cost }+ \text { follow on costs }}
$$

From a management perspective, Dell'Isola reflected the objective view in the definition (Dell’Isola, 1997):

$$
\text { Value }=\frac{\text { Function }+ \text { Quality }}{\text { Cost }}
$$

Before that, Walters and Lancaster also introduced the notion of value taking various interpretations, and more specifically in connection with customer satisfaction (Walters \& Lancaster, 1999). They argue that the traditional value chain begins with the company's core competences, whereas evidence suggests that modern value chain analysis reverses this approach and uses customers as its starting point.

Thomson et al (2003; 2006) argued that a common terminology is important when dealing with a wide variety of stakeholders and a value adding toolbox was suggested when addressing customer value expectations by means of problem solving (Lewis, 1996). They suggested that value is a trade-off, in terms of:

$$
\text { Value }=\frac{\text { Benefits }(\text { what you get })}{\text { Sacrifices }(\text { what you give })}
$$

which is an output/input viewpoint in which each stakeholder has a unique perspective. In the economic, financial, and accounting world, value is a fundamental topic connected with pricing or costing systems. In these systems, the "what you get” part and the "what you sacrifice” part are both always measured with price, cost, investment levels or some other financial measure. There are many approaches, from a simple balance sheet to complicated professional analysis tools for accounting and financial assessment to help value tangible or sometimes intangible objects.

\subsection{Valuing Information}

When information needs to be valued - for example in the calculation of either cost or benefits of information - the commonly used evaluation methods are inadequate because of its tangible and intangible characteristics. Past work on the subject mostly focuses on specific kinds of information from particular backgrounds. The following have been chosen for study: supply chain management, Value Of Information (VOI) for risk analysis, project management and business management including financial, banking, IT, and librarianship (Zhao et al., 2007).

a) In the domain of supply chain management, work has been undertaken on valuing the information shared throughout the supply chain using a number of mathematical models. The information flow direction, the inventory information and production plan information 
is a two-way communication between the downstream and upstream organisations in the supply chain. The sales information and demand forecasting information are the flows from downstream companies to their upstream partners. The value of information sharing lies in the quick and efficient sharing at the place where the downstream and upstream meet with each other (Ben-Haim, 2001; Dominguez \& Lashkari, 2004; Ferrer \& Ketzenberg, 2004; Gavirneni \& Kapuscinski, 1999).

b) In risk analysis or risk management in the engineering, financial, health, and environment sectors, Value of Information (VOI) analysis provides useful insights. VOI analysis evaluates the benefit of collecting additional information to reduce or eliminate uncertainty in a specific decision-making context. As noted in one of the earliest VOI applications: "no theory that involves just the probabilities of outcomes without considering their consequences could possibly be adequate in describing the importance of uncertainty to a decision maker”. VOI analysis makes explicit any potential losses from errors in decision making due to the uncertainty and it also identifies the "best" information collection strategy, which leads to the greatest net benefit to the decision maker (Yokota \& Thompson, 2004).

An analysis of VOI applications reveals a tendency to focus on demonstrating the usefulness of such an approach rather than to the influence on actual management decisions or evaluations tools. Among these solutions, the simplest VOI application for uncertainty is the decision tree. Little work has been done for complex continuous input but Yokota and Thompson (2004) give a review of a possible solution of this and suggests that strategies should be generated after the information has been gathered, when dealing with nonlinear continuous information inputs. The combination of Bayesian decision theory and other constraints that are relevant to information might be used to diagnose the overall system risk. Mussi developed a methodology for building a theory-based VOI sequential decision support system, and a design engine to build step-by-step knowledge-base and the related inference (Mussi, 2004).

c) In the management domain, industries like construction, aerospace, automotive and healthcare are context-dependent and involve proprietary information. Decision-makers may find it difficult to value a piece of information especially if it has no intrinsic value (BroadyPreston \& Williams, 2004) and is time-dependent. Methods have been devised to assess information value in relation to the profitability of a company, but are usually simple and ignored the rationale of the decision-makers. Pickard \& Dixon (2004) argued that the rationale will be affected by cognitive, affective and social variables. However, these approaches were not sufficiently comprehensive to cover the intangible dimensions of the 
information. Overall this work showed the importance of information value but did not divulge detail mechanisms to value individual information assets.

Knowledge derived from 'valuable' information, drives business and organisation success. Thus information can be a key asset of a company and is often multi-dimensional with sources such as the product, customer, market, human resource, management, supplier, account, business process, and specialist knowledge (Oppenheim \& Stenson, 2000). However, it can be detrimental to the daily and even long-term operation of a company if information is not properly managed or is unavailable. Information is organic (as it has a life cycle of being reused, maintained and updated), mechanic (as it increases productivity and competitiveness of a company) and dynamic (as it is time dependent). The value of information also depends on the context. The use of information in turn depends on access, tools and sequences (Cleveland, 1999).

d) The information evaluation research in the domain of IT has been mainly focused on search and retrieval. Finding information seems no longer to be the major challenge of the state-ofart search engines. Trying to convey relevant information rather than just data (where data is regarded as information without context) seems to be a major concern nowadays. A simple search engine scoring system for electronic documents, as the dominant form of project information, may not be efficient enough for the large quantities of modern information. Several attempts on this issue are more or less using value related solutions on both general information and/or documents (Galzer, 1993; Lee, 2001; Weide \& Bommel, 2006).

e) Other fields in which the value of information has been researched include librarianship. Fenner (2002) gives a general summary about how to place value on information. Weissinger (2005) gives a theoretical basis and analysed the materialist, idealist and critical metaphysical theories about the evaluative nature of information.

The above methods represent the state of the art in activities associated with the "evaluation" of information. They describe the key issues and some of the factors relevant to large engineering projects. However none describe specific techniques that would be directly applicable to engineering design information. It is clear that to undertake an information 'valuing' activity will require some means of defining the information entities and an associated overall process. We therefore propose the establishment of information characteristics, with associated metrics.

\subsection{Information characteristics}

Information characteristics can represent the nature of the information and assist the measurement of information quality or value. Zhao et al. (2007) have introduced an approach to identify the key 
information characteristics, in which a set of common evaluation criteria were derived from the literature. Seven key characteristics were proposed, namely:

$\cdot$ Accessibility •Usability • Currency • Context • Accuracy • Availability • Relevance Accessibility was the highest ranking information characteristic because information transactions and sharing play a big role in the literature. Accessing the right information at the right time is vital in an information transaction process, but not, we would argue, in research that treats information as an object with a value tag. For this reason the Accessibility criteria was omitted.

Other characteristics, not prevalent in the literature, may be important and could emerge from on going industry-based investigations of the information evaluation process. Nevertheless, the method of identifying the information characteristics and using them as the basis of the evaluation process has a sound basis.

\section{An Information evaluation approach}

\subsection{The framework}

In the last section, an instance of key information characteristics identified from the literature reviews has been introduced. But there are two more issues that need to be considered and two hypothesises are proposed before using them to build an overarching information evaluation process.

- Information Quality does not equal Value. Information value has both implicit (information itself) and explicit (the environment of the information) attributes and information quality can only be regarded implicit (Galzer, 1993). Some explicit elements will influence the value. The characteristics such as: Accessibility, quality. So the first hypothesis is: the Context or more specifically, the Relevance and the Impact are explicit factors that affect the value, judged from the result of analysis. For example, a person's bank statement is clearly a high quality piece of information judged on the basis that it is accurate, useful and up-to-date; is from a trusted source; and relevant information can be accessed. But the statement is of low value if it is evaluated in an unrelated work context and therefore the "Relevance" level is low in this particular context. Another example is in a situation of an information privation, the value of any information that can be found is significantly increased by the factor of "Impact". Referring to the trade-off between 'what you get' and 'what you give' in equation (4), information value is a trade-off between 'benefits of having information' and 'resources spending on storing and retrieving'. It is noted that 'Relevance to a problem', 'Impact of having the information', and 'Quality' inform benefits that needs to be further elaborated. 
- Cost. Although the list in Section 2.4 does not include Cost, it has been shown that the various definitions of value have in common a sacrifice part, which most often expressed as Cost (but also there can be other losses such as: time, effort, resources, opportunities as well as negative outcomes). Cost is the key factor representing the 'resources spending on storing and retrieving' part of the definition of information value and it is the second hypothesis.

From these two hypothesises:

$$
\text { Information value }=\frac{\text { Quality }+ \text { Relevance }+ \text { Impact }}{\text { Cost }}
$$

Based on the analysis result of the characteristics list and the two hypothesises, an information evaluation framework can be represented as shown in Fig. 1.

\section{“Take in fig. 1 "}

From this framework, the Information Quality can be quantified by measuring the information characteristics such as: Accuracy, Usability and so on (or any other characteristics identified from other approaches). Given the Information Quality the Information Value can be calculated using Equation (5) with addition inputs of Relevance, Impact, and Cost. The linkage among them is based on Bayesian Network, which is introduced in the next section. This framework just gives a qualitative method of information evaluation and the next step is to find an approach to quantitatively express the information characteristics and calculate the relationship between them and the information value.

\subsection{The Bayesian Network}

The Bayesian Network (BN) is a graphical tool that combines elements of both graph and probability theory. It has been shown that BNs are Directed Acyclic Graphs (DAG) with a set of probability tables (Russell, 2003). A BN encodes the probability distribution of a set of random variables by specifying a set of conditional independence assumptions together with a set of relationships among these variables and their related joint probabilities. In general the DAGs can model the set of relationships among the variables; each of a DAG's nodes represents a variable, and the arcs, which represent statistical dependence relations among the variables and local probability distributions for each variable given values of its parents, are the causal or influential links between the variables. A set of conditional probability functions associated with each node model the uncertain relationship between the variable and its parents. BNs' conditional independence assumptions yield more compact models than those based on full joint probability distributions, relaxing the issue of computational complexity when consider a large number of 
variables (Russell, 2003). The nature of the BN makes it a potentially powerful representation combining formalism with visual expression.

Basically, the Bayesian roles are: For any two events, A and B,

$$
p(B \mid A)=\frac{p(A \mid B) \times p(B)}{p(A)}
$$

where ' $\mathrm{p}(\mathrm{A})$ ' can be regarded as “the probability of $\mathrm{A}$ ”, and ' $\mathrm{p}(\mathrm{A} \mid \mathrm{B})$ ' is "the probability of A given that B has occurred".

Taking Information Quality and Trust in the information evaluation framework in Figure 1 as an example, the probability of "Information Quality” (is high, mid, or low), can be calculated as:

$$
p(\text { Quality } \mid \text { Trust })=\frac{p(\text { Trust } \mid \text { Quality }) \times p(\text { Quality })}{p(\text { Trust })}
$$

More generally given nodes $\mathrm{X}=\mathrm{X}_{1}, \ldots, \mathrm{X}_{\mathrm{n}}$, the joint probability function for any Bayesian Networks is:

$$
p(X)=\prod_{i=1}^{n} p\left(X_{i} \mid \text { parents }\left(X_{i}\right)\right)
$$

An example can be used to illustrate the basic elements of $\mathrm{BN}$ - the nodes, arcs, and prior and conditional probabilities and more importantly, the potential of implanting it into the information evaluation framework (Tang \& Nicholson, 2007). A physician wants to reason about the chance that a patient with a cough has lung cancer. The first relevant causal factor needing to be established would be whether the patient is a light, heavy or non-smoker. A possible diagnostic tool would be to take an X-Ray of the lungs. Fig. 2(a) shows a BN model for this example. In this model, each node with parents has a Conditional Probability Table (CPT), which, for each combination of the values of the parents, gives the conditional probability of its. Thus the CPT can be considered to quantify the strength of the causal relationships.

The CPT in Fig. 2 (a) can be further explained as follow. For the node of "Smoking", statistics shows that 0.70 (70\%) people don't smoke; 0.2 (20\%) are light smokers and 0.1(10\%) are heavy smokers. The second CPT table gives the probability of people get "Lung Cancer" given their smoking conditions $[\mathrm{P}($ Lung Cancer $=$ True $\mid$ Smoking $)]$. It shows that the probability of getting Lung Cancer for “No Smoker” is 0.01 (1\%), “Light” Smoker is 0.05\%, and “Heavy” smoker is 0.10(10\%). The next two CPTs show the probability of "Cough" given their Lung Cancer conditions (i.e. the chance of patients cough when they have or haven't lung cancer), and the probability of “X-Ray” symptom given their Lung Cancer conditions. 
With the constructed BN model, posterior probabilities can be calculated as shown in Fig. 2(b). It shows the physician's prior beliefs before any observations or evidence are taken into account, in another words, without any inputs. The marginal probability distribution is represented by the bars in the diagram. Any user inputs into any nodes in the network produce new probability distributions over all the variables in the network. Fig. 2(c) shows the physician's beliefs after diagnostic reasoning given that the patient has a cough, while Figure 2(d) shows how the chance of the patient having a lung cancer, with the positive lung X-Ray increases substantially when the patient is a heavy smoker. From the introduction about BN and the illustration example, it is easy to see the potential of implementing the $\mathrm{BN}$ to the information evaluation framework and regarding each of the characteristics in the framework as a node. The probability of information value (High, Mid or low) can be calculated through this method given the CPT of each of the information characteristics (good, mid or bad). In the next section, a BN based information evaluation assessment model is introduced.

“Take in fig. 2"

It can be seen that the BN is highly reliant on the statistical data from a sample from a large volume object. The statistical data can be transformed into CPT, which is the basis of a BN model, but a BN model needs to be trained before it can be used.

\section{Information evaluation model - a test case}

In the previous sections, a framework of information evaluation has been established using information characteristics as nodes and a Bayesian Network as the linkage. An information evaluation model has then been set up using documents from a real engineering project. This section introduces the engineering project, the training process of the $\mathrm{BN}$ and the model verification.

\subsection{The simplified framework}

In Section 3.1., an information evaluation framework has been established. Before implementing it, some works need to be done to make it suit the test case. In this circumstance of the test case, the 'Cost' is not taken into account because of the nature of the documents used, which means all the 'what you give' parts of the value definition are equal. The impacts of having all the documents are mainly time and resources that can be saved when these documents are reused, therefore 'Impact' here can be interpreted as 'Saving'. Then the tailor made information evaluation framework for this test case is:

$$
\text { Information value }=\text { Quality }+ \text { Relevance }+ \text { Saving }
$$




\subsection{The training process}

In this test case the engineering director's project folder is picked up as the background. This folder contains 60 documents including: technical specifications and procedures, meeting agendas, fax (order forms), letters (order related), notices, reports, and memos. The scenario is set as: the document management department needs to evaluate and archive these documents after the project has finished. The training process is shown in Fig. 3. In this training process, the document manager, or whoever is acting as the document manager with the knowledge of making the judgements, accesses each of the 60 documents using a questionnaire (Fig. 4).

For each document, he or she needs to make a judgement about each information characteristic identified in the framework (in Section 3.1) with some help of the definitions and question to be asked as shown in the two middle columns in Fig. 4. For example: the Accuracy of this document is (Good, Mid, or Bad); Trust level of this document (Yes or No), and so on. Also he or she needs to make Quality (High, Mid or Low) and Value (High, Mid or Low) judgements after the judgements of the information characteristics have been made. This is for the purpose of building a link between the characteristics and the value. When the questionnaires have been completed, all the inputs need to be re-organized into a Summary form and then calculated to build a CPT as shown in Fig. 3. The CPT represents every line linkage in Fig. 1 mathematically and it is the basis for BN model.

“Take in fig. 3” \& “Take in fig. 4”

Having developed the evaluation framework using appropriate information characteristics as the criteria and constructed the CPT for a BN tool which can provide both probability computing and graph support, an information evaluation assessment model can be constructed. The Fig. 5 shows the anterior evaluation model prior to the judgement of any information characteristics. The CPT behind each node with parent node(s) is built on historical statistic data which represents the probability gained from the training circumstance. For example, the 60 documents that were evaluated have a 58 percent of chance of being high Accuracy, and 73 percent of chance that it can be trusted, and so on.

\section{"Take in fig. 5”}

If there is enough evidence to support the judgement on each characteristic, and there is also available input (however defined) for Relevance and Saving, both the quality and value of information can be computed as shown in Fig. 6. It can be seen in this example that when the information evaluator thinks that the Accuracy is good, the information can be trusted, and it is usable and up to date (Currency); then the information has a 99 per cent probability of being high quality. Once the quality of the information has been assessed, the next step is judging the context 
to decide the relevance level, and assess the saving (savings when being reused, for example). Here, the evaluator estimates that the information is relevant to the context and the saving is Big, which gives a 98 per cent probability of information being high value, and so on.

“Take in fig. 6”

\subsection{The verification process}

When the model has been established on the basis of the training process using the 60 documents as a test case, it is necessary to validate this model against the training documents in order to judge the difference between the human judgement and the calculation results. The verification process is shown in fig. 7 and was to input just the information characteristic judgements from the training process summary form into the model and calculating each of the possibilities of the Quality and Value being high, mid, or low; Then compare them with the Quality and Value judgements from the training process. For example, the judgment for one document in the training process is: Accuracy(Good), Trust(Yes), Usability(Very), Currency(Yes), Relevance(High), Saving(Big). These judgements are input into the model and the model indicates that the probability of the Quality of this document being high is: 99\%; and the Value being high is $98 \%$. When checking the training process, the judgements indicate that the Quality and Value of this document are both high. This can be seen that the model is reasonably accurate and gives strong possibility on the right Value judgement. Two radar diagrams can be visualise the results as shown in Fig. 8.

“Take in fig. 7” \& “Take in fig. 8”

It can be seen that the model gives relevant precision possibilities both on Quality and Value, where the difference between model predictions and training judgments are less than 14\% for Quality and 5\% with Value for the 60 documents. To summarize, the Quality calculation and Value calculations have an 87 and 95 percent chance of giving an accurate result, which is defined here as more than a 90 percent probability that the Quality/Value is high, mid or low. It can be seen that there are some inaccurate calculation from the model, for example, document No. 42 and 43 are judged as high Quality and high Value in the training process, but as it is shown in Fig. 7, the model only gives a 45 percent of probability of being high Quality and 44 percent of probability of being high Value. This difference has been further analyzed and it is identified that the inconsistency during the training process is responsible for this significant difference. In another word, giving the same information characteristic judgments (Accuracy, Usability, and so on), the training process gives different Quality and Value judgments. This inconsistency confuses the model later and can be avoided during the training process. 


\section{Discussion and Further work}

With an information evaluation framework and assessment model, information can be evaluated based on the judgement of the various information characteristics criteria. But there are some contextual questions that need to be addressed. How much does the context affect the value judgement? Does the information have a unique value in different contexts? How can the context or relevance be classified? And how big is the impact of the value judgement within the context? These issues, and more importantly, the analysis that leads to a possible decision support approach are considered below.

\subsection{Multi - context evaluation}

A number of case studies have been identified in the engineering and construction field [49] and we have described 'value' in a number of contexts [31][19]. Hence we can propose a number of contexts for the evaluation of information.

- Any evaluation process is clearly context sensitive therefore the results of evaluation are also context depended. Not only the results, but the process, the judgement criteria and the manners of dealing with the information after evaluation process are different.

- An individual participating in an evaluation process can be a representative of him/her self, their department or the whole organization. In this circumstance, individuals must clarify the context in which they conduct the evaluation. This also does not necessarily require the framework to be same, in fact the criteria or even the parameters in the calculation could vary.

- In a typical evaluation process, information flows are treated differently, applying a Department Evaluation or Personal Evaluation approach according to the context. More broadly, apart from the enterprise and personal level contexts, there may still be other contexts, such as the "Corporate” level and where the information evaluation decision affects the whole corporate operation. Although the accurate definition of each of those contexts, such as the corporate, the department, the personal, is not present, their existence is obvious. So the hypothesis here is that the context is multiple for the information evaluation process, which means the information evaluation model developed in Section 3 can be regarded as an instance of the information evaluation that fills into either of the contexts, and can be tailored to suit for the particular requirements.

\subsection{Further work}

Further issues need to be discussed about this approach for more research and implements: 
a) The information characteristics and the other criteria such as relevance, context, cost, and impact are high level. Not only could the criteria be changed in a different modelling approach, but also the method of measurement. It is thus required to establish metrics for each of the characteristics and it is anticipated that more human factors need to be taken into account;

b) The definition and measurement for context is a topic of much research and there may be more levels of context rather than just corporate, department, and personal; [12] [14]

c) The model relies on the CPT (Conditional Probability Table) behind the diagrams which requires considerable statistical work to obtain the data CPT in a formalized manner;

d) The approach uses the Bayesian theory as the basis of the computation of the model, which can be reversed for reasoning inference. Take equation (7) as an example, it can be expressed as:

$$
p(\text { Trust } \mid \text { Quality } \mid)=\frac{p(\text { Quality } \mid \text { Trust }) \times p(\text { Trust })}{p(\text { Quality })}
$$

The approach developed for the evaluation process uses the information characteristics like trust, accuracy, and so on to calculate the quality and then the value of information. But an equation like (9) can be manipulated to assist information searching. For a circumstance where the information already exists and the job is to locate some particular information with certain characteristics, a reversed Bayesian equation could be the basis of calculation for a probability of certain characteristics such as trust level.

\section{Concluding remarks}

This paper has developed an approach to build on an information evaluation assessment system based on the information characteristics, Bayesian Network theory, and conditional probability statistical data. This approach uses information characteristics which can be judged against each information instance, as the fundamental elements to build the nodes of Bayesian Network; and then make conditional probability statistical data to build the links among them; and finally applies Bayesian theory to calculate the possibility of information value given the judgment input on information characteristics. From the test case study with a model training process and a verification one, it can be concluded that this approach can be used to build information evaluation model that gives relevant precision possibilities both on information quality and information value. Additionally the multi level context has been discussed and three levels, which are: cooperate, department, and personal level of context for information evaluation have also been identified. Several topics of further works for research and implements are raised with some in depth analysis 
of the methodology. The key issue is the potential high workload in collecting the probability data in the CPT (Conditional Probability Table) which is the core of the calculation of the evaluation. But with the potential of applying the Bayesian theory reversely into reasoning inference, this approach can also be used to design the information search system or flexible archiving system.

\section{Acknowledgements}

The contribution of the KIM project team and its industrial collaborators to the development of the research programme and thus to this paper is gratefully acknowledged. The KIM project is funded by the UK Engineering and Physical Sciences Research Council (EPSRC) and the Economic and Social Research Council (ESRC) under Grant Numbers EP/C534220/1 and RES-331-27-0006.

\section{References}

Ben-Haim, Y. (2001). Info-gap value of information in model updating. Mechanical Systems and Signal Processing, 15(3), 2001, 457-474.

Broady-Preston, A. T., \& Williams, J. (2004). Using information to create business value: City of London legal firms, a case study. Performance Measurement and Metrics, 5(1), 5-10.

Butcher, H. (1995). Information overload in management and business. IEE_Colloquium Digest, 95(223), 1-2.

Cleveland, A. B. J. (1999). Harvesting the Value of Information. Journal of Management in Engineering ASCE, 15(4), 37-42.

Dell'Isola, A. (1997). Value engineering: Practical applications for design, construction, maintenance and operations. Kingston, MA: RS Means.

Dent, N. (1995). Value. In: Honderich, T. (Eds.), The Oxford companion to philosophy. Oxford: Oxford University Press.

Dominguez, H. \& Lashkari, R. S. (2004). Model for integrating the supply chain of an appliance company: A value of information approach. International Journal of Production Research, 42(11), 2133-2140.

Edmunds, A., \& Morris, A. (2000). The problem of information overload in business organisations: a review of the literature. International Journal of Information Management, 20(1), 17-28.

Eppler, M. J., \& Mengis, J. (2004). The concept of information overload: a review of literature from organization science, accounting, marketing, MIS, and related disciplines. The Information Society, 20(5), 325-344.

Feather, J. (1998). The information society: A study of continuity and change. London: Library Association.

Fenner, A. (2002). Placing value on Information. Library Philosophy and Practice, 4(2), 2002, 6.

Ferrer, G., \& Ketzenberg, M. E. (2004). Value of information in remanufacturing complex products. IIE Transactions, 36(3), 265-277.

Fowler, T. C. (1990). Value analysis in design. New York: Van Nostrand Reinhold.

Galzer, R. (1993). Measuring the value of information: the information-intensive organization. Technical IBM System Journal, 32(1), 1993, pp. 99-110.

Gavirneni, S. \& Kapuscinski, R. (1999). Value of information in Capacitated Supply Chains, Management Science, 45(1), 16-24.

Hicks, B. J. \& Culley, S. J. (2002). A framework for the requirements of capturing, storing and reusing information and knowledge in engineering design. International Journal of Information Management, 22(4), 263-281.

Inc. Staff (2003). Data INC Magazine. Available at: http://www.inc.com/magazine/19990101/715.html 
Kohler, W. (1966). The place of value in a world of facts. New York: Liverlight.

Ladley, J. (2004). Stay informed: online column beyond the data warehouse: the value of information. Available at: http://www.datawarehouse.com/article/.

Lee, C. S. (2001). Modelling the business value of information technology. Information \& Management, 39(3), 191-210.

Lewis, D. (1996). Dying for information? London: Reuters Business Information.

Miles, L. D. (1972). Techniques of value analysis and engineering. New York: McGraw Hill.

Mussi, S. (2004). Putting value of information theory into practice: a methodology for building sequential decision support systems. Expert Systems, 21(2), 92-103.

Oppenheim, C. (1997). Managers' use and handling of information. International Journal of Information Management, 17(4), 39-248.

Oppenheim, C., \& Stenson, H. (2000). Valuing information assets in UK companies. Managing Information, 7(3), 56-61.

Pickard, A. J., \& Dixon, P. (2004). Measuring electronic information resource: towards a transferable quality framework for measuring value. The Journal of Information and Knowledge Management Systems, 34(3), 126-131.

Thomson, D. S., Austin, S. A., Devine-Wright, H., \& Mills, G. R. (2003). Managing Value and quality in design. Building Research \& Information, 31(5), 334-345.

Thomson, D. S., Austin, S. A., D.S. Root, D. S., \& A. Thorpe, A. (2006). A problem-solving approach to value-adding decision making in construction design. Engineering Construction and Architectural Management, 13(1), 43-61.

Walters, D. \& Lancaster, G. (1999). Value and information-concepts and issues for management. Management Decision, 37(8), 643-656.

Weide, T.P.v.d. , \& Bommel, P.v. (2006). Measuring the incremental information value of documents. Information Sciences, 176(2), 91-119.

Weissinger, T. (2005). Information as a value concept: reconciling theory and practice. Library Philosophy and Practice, 8(1), 1-12.

Woodruff, R. B., \& Gardial, S. F. (1996). Know your customer: New approaches to understanding customer value and satisfaction. Cambridge MA: Blackwell.

Yokota, F., Thompson, K, M, (2004). Value of information analysis in environmental health risk management decisions: Past, present, and future. Risk Analysis, 24(3), 635-650.

Zhao, Y. Y., Tang, L. C. M., Darlington, M. J., Austin, S. A., \& Culley, S. J. (2007). Establishing information valuing characteristics for engineering design information. International Conference on Engineering Design, ICED’07, 28-31 August 2007, CITE DES SCIENCES ET DE L'INDUSTRIE, Paris, France.

Russell, S., \& Norvig, P. (2003). Artificial Intelligence: A Modern Approach. (2nd ed.). NJ: Prentice-Hall.

Tang, A., \& Nicholson, A. (2007). Using Bayesian belief network for change impact analysis in architecture design. The Journal of Systems and Software, 80(1), 127-148.

Tang, L. C. M., Austin, S. A., Zhao, Y. Y., Culley, S. J., \& Darlington, M. J. (2006). Immortal information and through life knowledge management (KIM): how can valuable information be available in the future? The 3rd Asia-Pacific International Conference on Knowledge Management, KMAP2006, $11^{\text {th }}$ to $13^{\text {th }}$ December, 2006, The Hong Kong Polytechnic University, Hong Kong. 


\section{High Value Information in Engineering Organizations}

\section{Figure Legends:}

Fig. 1. Information evaluation framework

Fig. 2. A medical example: (a) BN nodes, arcs and CPTs; (b) BN graph without evidence; (c) patient has a cough(diagnostic reasoning); (d) patient has a cough and a heavy smoker (both predictive and diagnostic reasoning).

Fig. 3. Training process for information evaluation model

Fig. 4. Questionnaire for training process

Fig. 5. Anterior information evaluation model

Fig. 6. Posterior information evaluation model with input

Fig. 7. Verification process

Fig. 8. Training judgments and model calculation comparison 


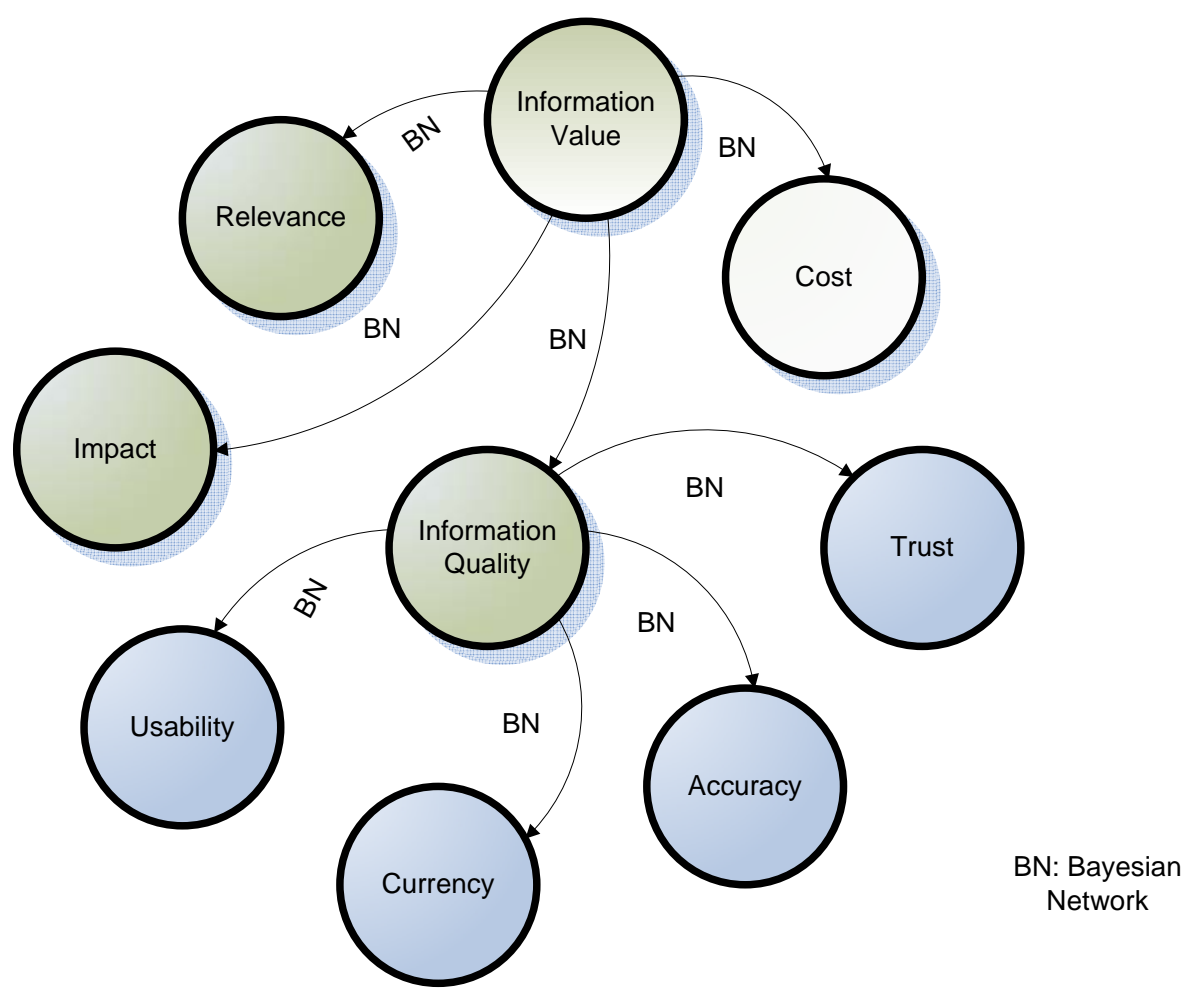

Fig. 1. Information evaluation framework 


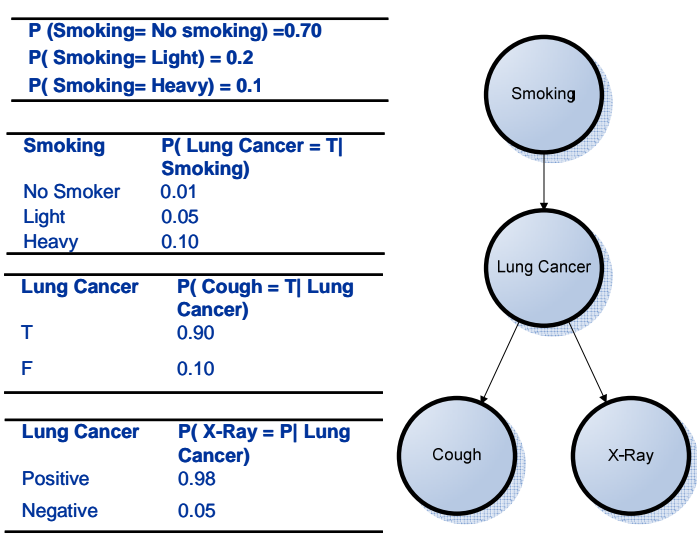

(a)

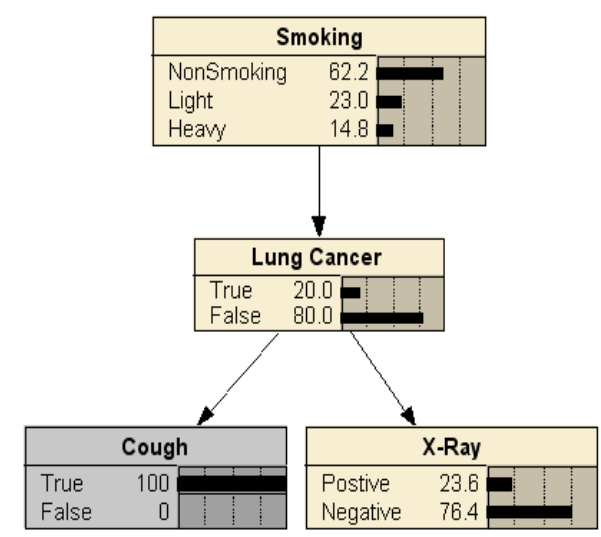

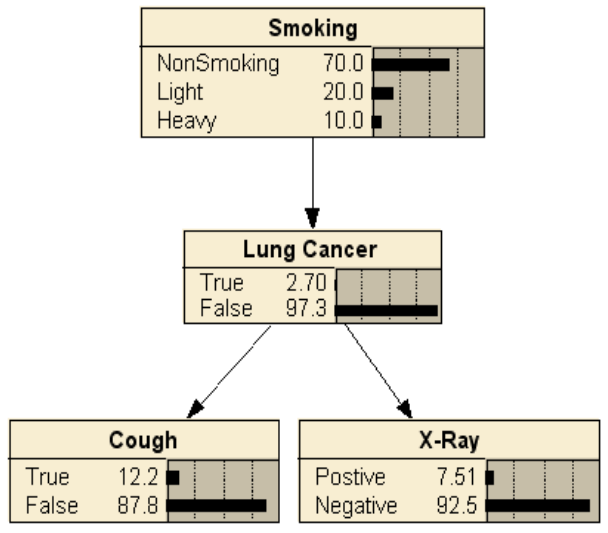

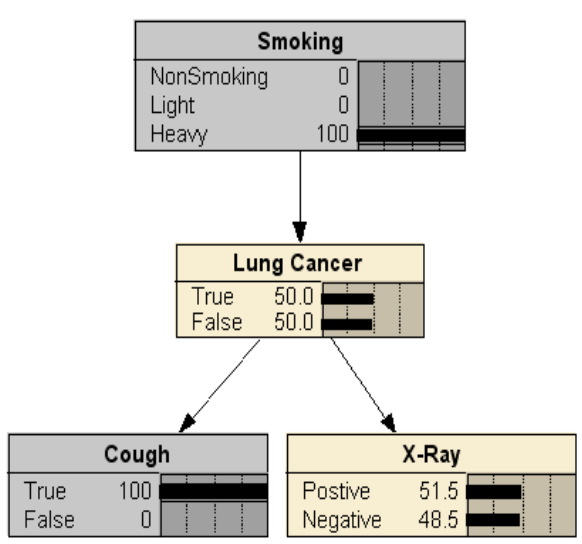

Fig. 2. A medical example: (a) BN nodes, arcs and CPTs; (b) BN graph without evidence; (c) patient has a cough(diagnostic reasoning); (d) patient has a cough and a heavy smoker (both predictive and diagnostic reasoning). 


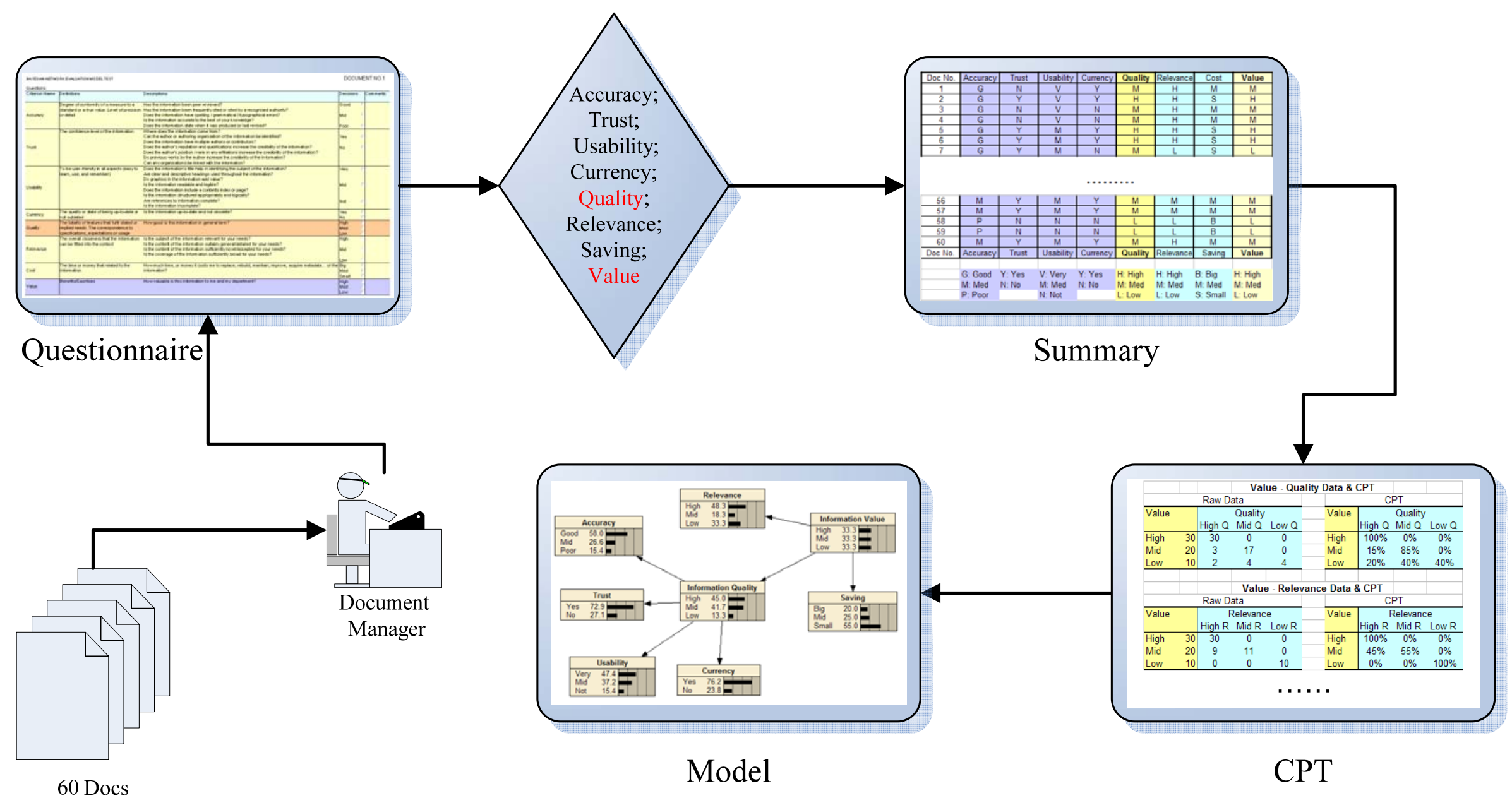

Fig. 3. Training process for information evaluation model 


\begin{tabular}{|c|c|c|c|c|}
\hline \multicolumn{3}{|c|}{ BAYESIAN NETWORK EVALUATION MODEL TEST } & \multicolumn{2}{|c|}{ DOCUMENT NO. } \\
\hline Questions: & & & & \\
\hline Criterion Name & Definitions & Descriptions & Decisions & Comments \\
\hline Accuracy & $\begin{array}{l}\text { Degree of conformity of a measure to a } \\
\text { standard or a true value. Level of } \\
\text { precision or detail }\end{array}$ & $\begin{array}{l}\text { Has the information been peer reviewed? } \\
\text { Has the information been frequently cited or cited by a recognised authority? } \\
\text { Does the information have spelling / grammatical / typographical errors? } \\
\text { Is the information accurate to the best of your knowledge? } \\
\text { Does the information state when it was produced or last revised? }\end{array}$ & $\begin{array}{l}\text { Good } \\
\text { Mid } \\
\text { Poor }\end{array}$ & \\
\hline Trust & The confidence level of the information & $\begin{array}{l}\text { Where does the information come from? } \\
\text { Can the author or authoring organisation of the information be identified? } \\
\text { Does the information have multiple authors or contributors? } \\
\text { Does the author's reputation and qualifications increase the credibility of the information? } \\
\text { Does the author's position / rank in any affiliations increase the credibility of the information? } \\
\text { Do previous works by the author increase the credibility of the Information? } \\
\text { Can any organisations be linked with the information? }\end{array}$ & $\begin{array}{l}\text { Yes } \\
\text { No }\end{array}$ & \\
\hline Usability & $\begin{array}{l}\text { To be user-friendly in all aspects (easy } \\
\text { to learn, use, and remember) }\end{array}$ & $\begin{array}{l}\text { Does the information's title help in identifying the subject of the information? } \\
\text { Are clear and descriptive headings used throughout the information? } \\
\text { Do graphics in the information add value? } \\
\text { Is the information readable and legible? } \\
\text { Does the information include a contents index or page? } \\
\text { Is the information structured appropriately and logically? } \\
\text { Are references to information complete? } \\
\text { Is the information incomplete? }\end{array}$ & Mid & \\
\hline Currency & $\begin{array}{l}\text { The quality or state of being up-to-date } \\
\text { or not outdated }\end{array}$ & Is the information up-to-date and not obsolete? & $\begin{array}{l}\text { Yes } \\
\text { No }\end{array}$ & \\
\hline Quality & $\begin{array}{l}\text { The totality of features that fulfil stated } \\
\text { or implied needs. The correspondence } \\
\text { to specifications, expectations or usage }\end{array}$ & How good is this information in general term? & $\begin{array}{l}\text { High } \\
\text { Med } \\
\text { Low }\end{array}$ & \\
\hline Relevance & $\begin{array}{l}\text { The overall closeness that the } \\
\text { information can be fitted into the context }\end{array}$ & $\begin{array}{l}\text { Is the subject of the information relevant for your needs? } \\
\text { Is the content of the information suitably general/detailed for your needs? } \\
\text { Is the content of the information sufficiently novel/accepted for your needs? } \\
\text { Is the coverage of the information sufficiently broad for your needs? }\end{array}$ & $\begin{array}{l}\text { High } \\
\text { Mid } \\
\text { Low }\end{array}$ & \\
\hline Saving & $\begin{array}{l}\text { The time or money that can be saved } \\
\text { using the information }\end{array}$ & How much time, or money this information can save when doing the same work? & \begin{tabular}{|l} 
Big \\
Med \\
Small
\end{tabular} & \\
\hline Value & Benefits/Sacrifices & How valuable is this information to me and my department? & $\begin{array}{l}\text { High } \\
\text { Med } \\
\text { Low }\end{array}$ & \\
\hline
\end{tabular}

Fig. 4. Questionnaire for training process 


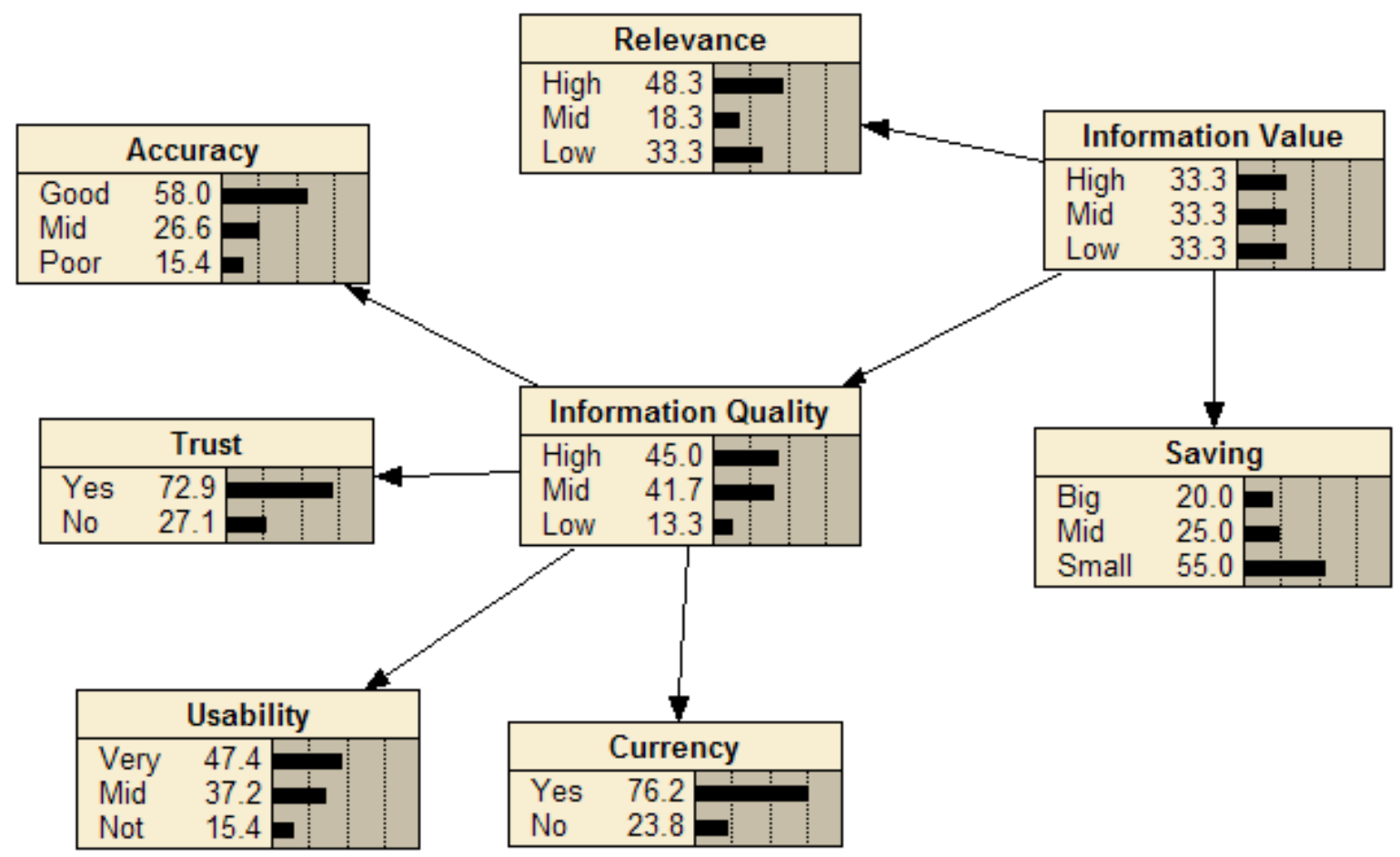

Fig. 5. Anterior information evaluation model 


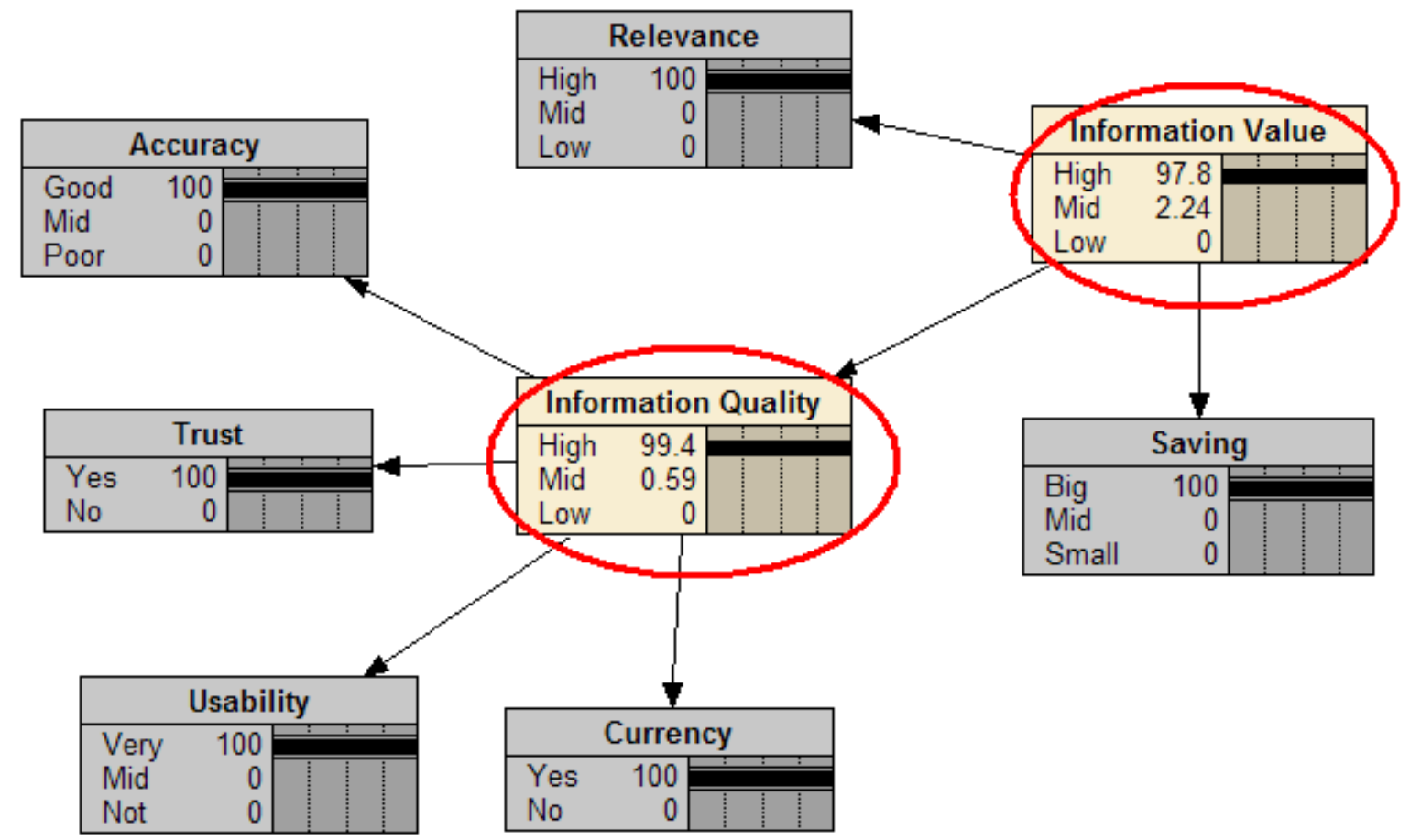

Fig. 6. Posterior information evaluation model with input 


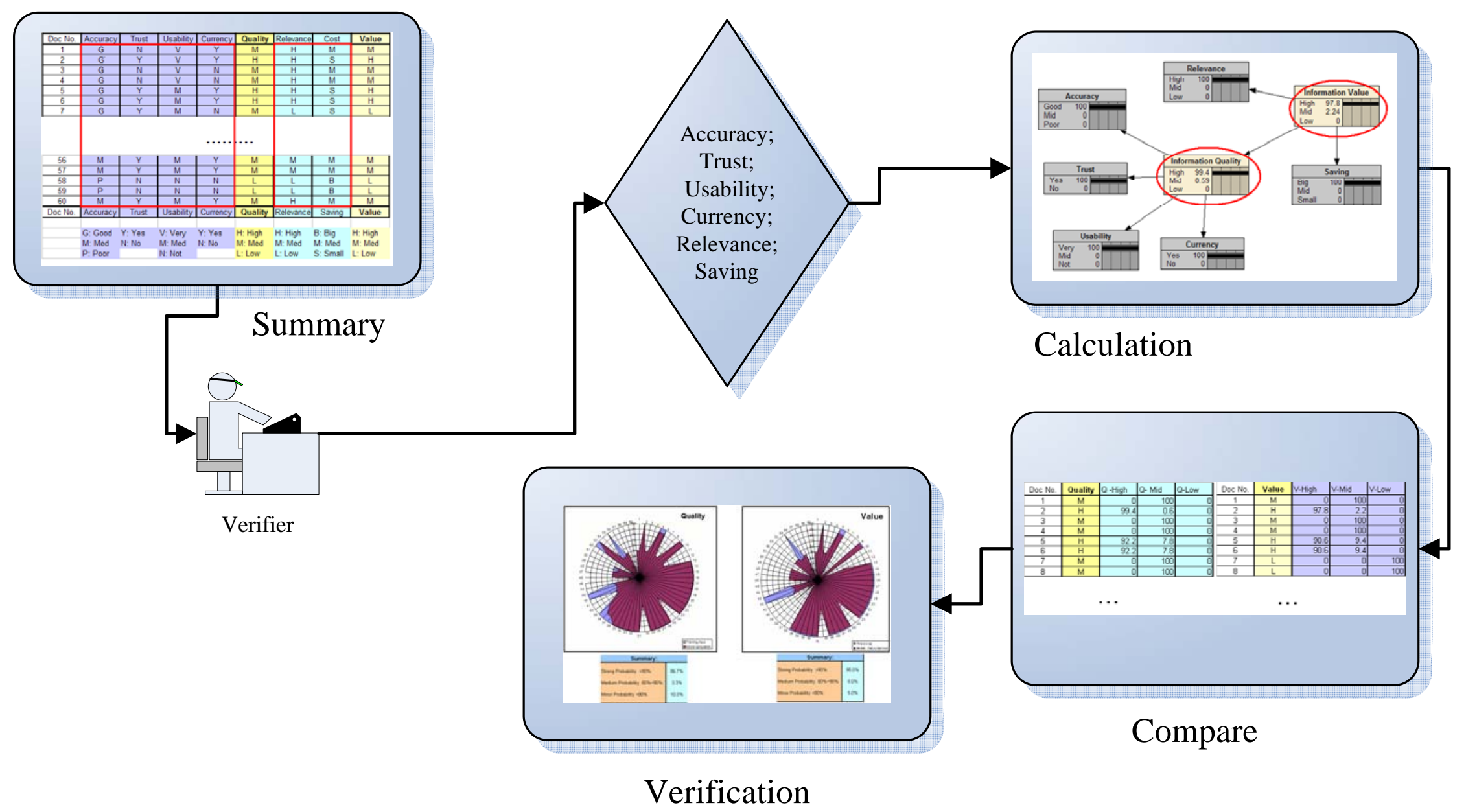

Fig. 7. Verification process 

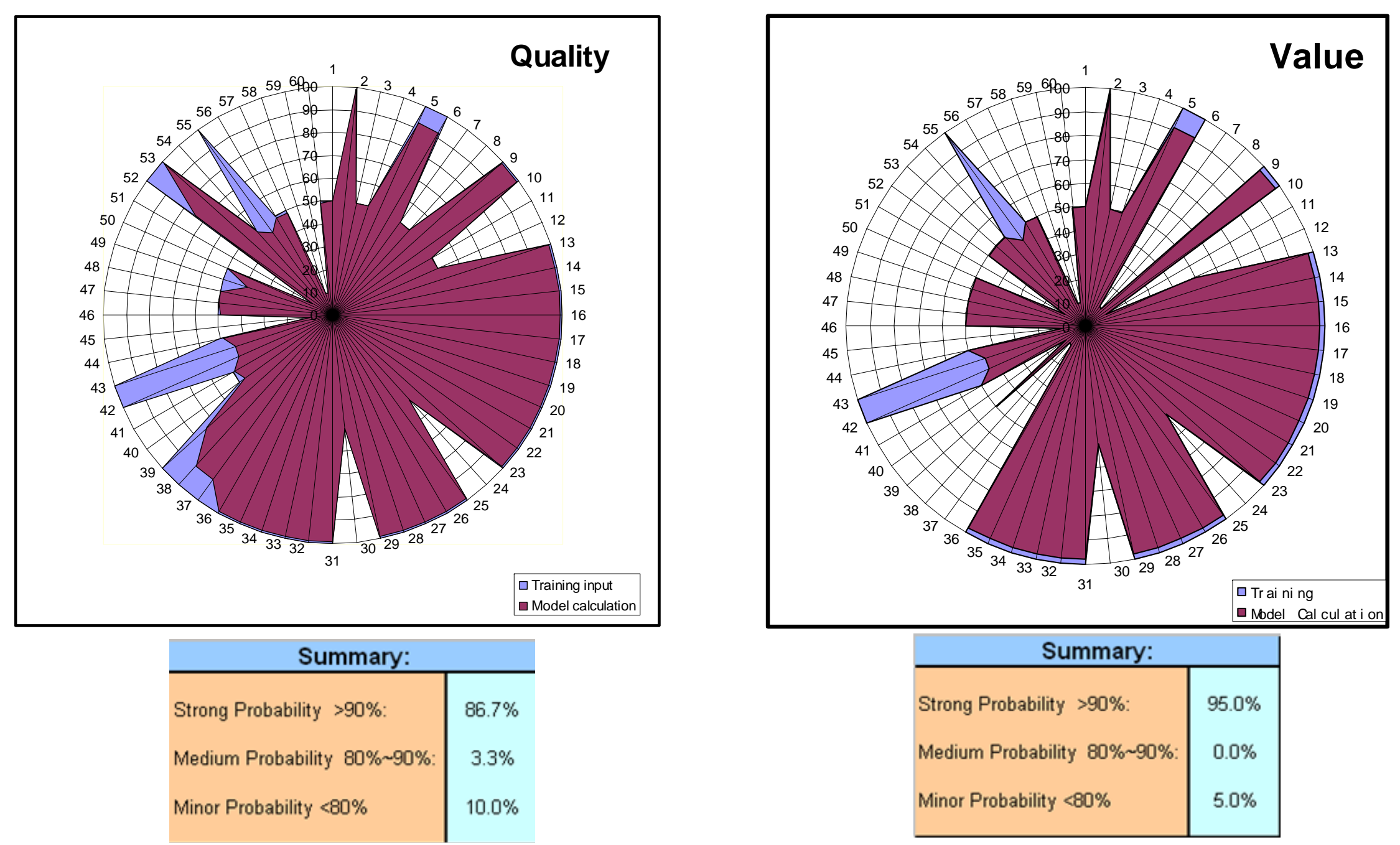

Fig. 8.Training judgments and model calculation comparison 